* Doutora em Direito das Relações Sociais pela Pontifícia Universidade Católica de São Paulo - PUC/SP. Mestre em Direito pela Universidade Estadual de Londrina - UEL/PR. Professora permanente do Programa de Mestrado e Doutorado em Direito da Universidade de Marília UNIMAR e do Programa de Mestrado em Direito e Cidadania da Universidade Paranaense UNIPAR/PR. Advogada.

E-mail: jussara@bflaw.adv.br

** Doutoranda e Mestre em Direito pelo Programa de Pós-graduação em Direito da Universidade de Marília - PPGD UNIMAR.

E-mail: mariamacenaadv@gmail. com

***Mestre em Direito pelo Programa de Pós-graduação em Direito da Universidade de Marília - PPGD UNIMAR.

E-mail: jgerminari@tjsp.jus.br

\section{O Princípio Da BoA-Fé E Os Reflexos Sobre A Proteção Ao Bem de Família: Aspectos Materiais E Processuais}

\author{
The Principle Of Good Faith And Reflections ON \\ Homestead: Material And Process Aspects
}

\section{Jussara Borges Ferreira* Maria das Graças Macena Dias de Oliveira** Jefferson Patrik Germinari***}

Como citar: FERREIRA, Jussara Borges; OLIVEIRA, Maria das Graças Macena Dias de; GERMINARI, Jefferson Patrik. O princípio da boa-fé e os reflexos sobre a proteção ao bem de família: aspectos materiais e processuais. Revista do Direito Público, Londrina, v. 16, n. 3, p. 227-244, dez. 2021. DOI: 10.5433/24157-108104-1.2021v16n3p.227. ISSN: 1980-511X

Resumo: O presente artigo tem por objetivo analisar a proteção jurídica dada ao bem de família no ordenamento jurídico atual, especialmente, a partir da interpretação constitucional à dignidade da pessoa humana relacionada com a Lei. 8009/90, do princípio da boa-fé objetiva e do princípio da função social dos contratos. Avaliar o critério de destinação do bem relacionado à proteção da tutela do mínimo existencial, mostra-se fundamental para correta interpretação do instituto jurídico mencionado, especialmente a partir do enfoque nos aspectos materiais e processuais. Utilizando pesquisa exploratória, bibliográfica e qualitativa, conclui-se que os recentes entendimentos jurisprudenciais que afastaram a proteção ao bem de família, em decorrência de violação da boa-fé objetiva - princípio jurídico do direito civil contratual -, há possibilidade de abalo considerável do sistema de proteção jurídica ao mínimo existencial e à perspectiva de concretização da função social dos contratos.

Palavras-chave: Bem de família; Boa-fé objetiva; Dignidade da pessoa humana.

Abstract: This article aims to analyze the legal protection given
to the homestead in the current legal system, especially from the
constitutional interpretation to the dignity of the human person
related to Law. $8009 / 90$, the principle of objective good faith
and the principle of the social function of contracts. Evaluating
the criterion of destination of the good, related to the protection
of the existential minimum guardianship, is fundamental for the
correct interpretation of the mentioned legal institute, especially
from the focus on the material and procedural aspects. Using 
exploratory, bibliographical and qualitative research, it can be concluded that recent jurisprudential understandings that departed from the protection of homestead due to violation of objective good faith, the legal principle of contractual civil law, there is a possibility of considerable disruption to system of legal protection to the minimum existential and the perspective of accomplishing the social function of the contracts.

Keywords: Homestead. Objective good faith. Dignity of the human person. 


\section{INTRODUÇÃO}

A proteção jurídica ao bem de família, dotando-o de impenhorabilidade e inalienabilidade é assunto que, frequentemente, é abordado pela doutrina e pelos tribunais, através de interpretações concebidas a partir de critérios jurídicos que muitas vezes podem ser efetivamente questionados.

Com o objetivo de propor reflexões críticas, o presente artigo tem como objetivo analisar a proteção ao bem de família a partir de um prisma constitucional, passando a enfrentar as controvérsias em relação à flexibilização em decorrência da aplicação do princípio da boa-fé objetiva, passando pela análise da legislação infraconstitucional, de direito material e processual.

Assim, na primeira seção, será abordada a proteção ao bem de família, a partir da exposição e fundamentação acerca de seu caráter constitucional, chegando-se até a regulamentação dada pela Lei n. 8.009/90. Na segunda seção, o enfoque recai sobre o princípio da boa-fé e sua irradiação no sistema jurídico como um todo, tratando dos aspectos constitucionais, do tratamento dado pela legislação civil e finalmente pela legislação processual civil vigente desde o ano de 2015. Por fim, na terceira seção, será analisada a interpretação do princípio da boa-fé e os impactos na proteção ao bem de família, especialmente após as recentes decisões do Superior Tribunal de Justiça.

Utilizando-se de pesquisa exploratória, bibliográfica e qualitativa, através do método dedutivo, busca-se verificar se a opção realizada pelo Poder Judiciário em flexibilizar a proteção ao bem de família se coloca como mitigação a preceitos constitucionais, podendo trazer efeitos danosos às relações contratuais estabelecidas e consequentes violações à dignidade da pessoa humana, fundamento da República Federativa do Brasil.

\section{PROTEÇÃO AO BEM DE FAMÍLIA NA ORDEM JURÍDICA INTERNA}

Busca-se aqui a localização da proteção ao bem de família dentro da ordem jurídica interna, partindo-se da análise do contexto constitucional vigente, para então ingressar na égide da Lei n. 8.009/90, responsável pela regulamentação infraconstitucional da proteção ao bem de família.

\subsection{Caráter Constitucional da Proteção ao Bem de Família}

Como ensinam Maristela Aparecida Dutra e Fernanda Aparecida Borges de Andrade (2017, p. 246), o instituto do bem de família tem origem nos Estados Unidos, no começo do século XIX, a partir da promulgação da lei Homestead Exemption Act, em decorrência de profunda crise econômica que refletia fortemente na questão habitacional.

Segundo Limongi França (1988, p. 117), apresentando conceito histórico, "bem de família é o imóvel urbano ou rural destinado pelo chefe de família, ou com o consentimento deste mediante escritura pública, a servir como domicílio da sociedade doméstica, com a cláusula de impenhorabilidade". O bem de família "[...] tem por escopo assegurar um lar à família ou meios 
para o seu sustento, pondo-a ao abrigo de penhoras por débitos posteriores à instituição, salvo as que provierem de tributos relativos ao prédio, ou de despesas condominiais" (DINIZ, 2019, p. 202).

Para abordar a questão da impenhorabilidade do bem de família, é imprescindível a análise sistemática do aparato constitucional trazido da Constituição Federal (CF) de 1988, especialmente, a partir da consagração da dignidade da pessoa humana como um dos fundamentos da República ${ }^{1}$, além de trazer previsões semelhantes na parte dos objetivos fundamentais ${ }^{2}$, assegurando mecanismos capazes de efetivação dessa dignidade, mesmo sem a verificação, no texto constitucional, de princípio que estabeleça critérios objetivos sobre o mínimo existencial.

Temos por dignidade da pessoa humana a qualidade intrínseca e distintiva de cada ser humano que o faz merecedor do mesmo respeito e consideração por parte do Estado e da comunidade, implicando, neste sentido, um complexo de direitos e deveres fundamentais que assegurem a pessoa tanto contra todo e qualquer ato de cunho degradante e desumano, como venham a lhe garantir as condições existenciais mínimas para uma vida saudável, além de propiciar e promover sua participação ativa co-responsável nos destinos da própria existência e da vida em comunhão dos demais seres humanos. (SARLET, 2001, p. 60)

Aliado ao texto constitucional vigente, é possível buscar na Declaração Universal dos Direitos Humanos ${ }^{3}$, a designação de elemento normativo internacional de proteção à dignidade da pessoa humana, identificado no sentido de que essa dignidade se refere a um nível mínimo de subsistência.

Assim, é possível incluir a proteção jurídica concedida ao bem imóvel considerado bem de família, tornando-o impenhorável, com a clara ideia de efetivação de proteção ao direito fundamental mínimo de moradia. Torna-se pertinente entender que a impenhorabilidade que aqui se menciona decorre da destinação do bem imóvel, sendo evidentemente desnecessária a declaração em escritura pública de Registro de Imóveis.

Trata-se de identificação do bem imóvel a partir de elementos ligados à existência, criandose, assim, o elo com a proteção constitucional à dignidade da pessoa humana, motivo pelo qual, em que pese estar prevista em lei federal, é evidente que a proteção ao bem de família tem viés

1 Art. $1^{\circ}$. A República Federativa do Brasil, formada pela união indissolúvel dos Estados e Municípios e do Distrito Federal, constitui-se em Estado Democrático de Direito e tem como fundamentos

$[\ldots]$

III. a dignidade da pessoa humana

2 Art. $3^{\circ}$ Constituem objetivos fundamentais da República Federativa do Brasil:

I - construir uma sociedade livre, justa e solidária;

II - garantir o desenvolvimento nacional;

III - erradicar a pobreza e a marginalização e reduzir as desigualdades sociais e regionais;

IV - promover o bem de todos, sem preconceitos de origem, raça, sexo, cor, idade e quaisquer outras formas de discriminação.

3 Art. 25.

I) Todo o homem tem direito a um padrão de vida capaz de assegurar a si e a sua família saúde e bem estar, inclusive alimentação, vestuário, habitação, cuidados médicos e os serviços sociais indispensáveis, e direito à segurança em caso de desemprego, doença, invalidez, viuvez, velhice ou outros casos de perda de meios de subsistência em circunstâncias fora de seu controle.

II) A maternidade e a infância têm direito a cuidados e assistência especiais. Todas as crianças, nascidas dentro ou fora do matrimônio, gozarão da mesma proteção social 
claramente constitucional.

Teresa Negreiros entende que, na classificação dos bens, o elemento inovador é precisamente a destinação existencial que, em contraposição à destinação patrimonial, eleva a pessoa, isto é, as necessidades humanas mais elementares, a ponto de referência para a individualização de espécies diversas de bens. O impacto deste enfoque existencial é particularmente nítido a respeito do bem de família (NEGREIROS, 2006, p. 433).

A partir do que foi apresentando, facilmente identifica-se a necessidade de moradia às necessidades mais básicas do ser humano, motivo pelo qual a ordem jurídica posta, tratou de proteger o único bem imóvel de determinada pessoa, utilizado como essencial à moradia familiar, com cláusulas de impenhorabilidade e inalienabilidade. Essas não constituem um fim em si próprio, mas sim, uma forma de garantir a residência do proprietário de um único imóvel, tornando-se a residência da família.

A proteção à família não reside no âmbito da vontade individual, mas no que concerne aos interesses não-patrimoniais, quando em choque com os interesses patrimoniais. Assim, há que se dispensar qualquer ato ou formalidade para a instituição do bem de família. Percebe-se que os critérios de interpretação das disposições de bem de família seguem uma análise de avaliação das reais necessidades pessoais.

Observa-se que o conteúdo do bem de família regulado pela lei supramencionada é mais abrangente e flexível do que o adotado pelo Código Civil, ou seja, embora pautado na defesa da moradia, não ignora outras necessidades dos seres humanos. A extensão do âmbito do bem de família tem sido progressivamente ampliada em relação às pessoas que possam ser beneficiadas. Trata-se de instrumento de garantia ao direito constitucional de moradia.

Considerando a relevância constitucional da proteção ao bem de família e também o fato de que sua relativização encontra respaldo justamente na interpretação do princípio da boa-fé, optouse neste trabalho tratar deste princípio de forma independente, em tópico próprio, dando-se assim o rigor metodológico necessário que o problema exige.

\subsection{Regulamentação Dada Pela Lei 8.009/90}

A par dos preceitos constitucionais vigentes a partir de 1988, nos quais se fundam a proteção ao bem de família, foi promulgada em 1990 a Lei n. 8.009, fruto da conversão da Medida Provisória 143/90, tratando a mesma do bem de família involuntário, ou seja, aquele assim considerado por determinação legal, independentemente da manifestação da vontade. Trata-se de imposição estatal, ganhando, assim, status de norma de ordem pública, com elementos axiológicos bastante claros: a defesa do direito de moradia e a proteção ao núcleo familiar, nos dizeres de Luiz Edson Fachin (2001, p. 164), “orienta-se pelo interesse social de assegurar uma sobrevivência digna aos membros da família, realizando, em última instância, a dignidade humana".

A partir de uma comparação com o conceito histórico sobre bem de família, o conceito atual de bem de família está previsto no art. $1^{\circ}$ da Lei 8.008/90, que dispõe: 
Art. $1^{\circ} \mathrm{O}$ imóvel residencial próprio do casal, ou da entidade familiar, é impenhorável e não responderá por qualquer tipo de dívida civil, comercial, fiscal, previdenciária ou de outra natureza, contraída pelos cônjuges ou pelos pais ou filhos que sejam seus proprietários e nele residam, salvo nas hipóteses previstas nesta lei.

Parágrafo único. A impenhorabilidade compreende o imóvel sobre o qual se assentam a construção, as plantações, as benfeitorias de qualquer natureza e todos os equipamentos, inclusive os de uso profissional, ou móveis que guarnecem a casa, desde que quitados (BRASIL, 1990).

Importante a compatibilização do texto acima com a expressão entidade familiar que consta dos $\S \S 3^{\circ}$ e $4^{\circ}$ do art. 226 da Constituição de 1988, no sentido de que a constituição do bem de família pode se dar por qualquer das formas de constituição da própria família, especialmente em um momento em que, tais conceitos são cada vez mais entendidos de forma ampla e abstrata.

Importante destacar que, a Lei 8.009/90 trata do bem de família involuntário ou legal, ao passo que o Código Civil vigente, nos seus artigos $1.711^{4}$ a 1.722 , trata do bem de família voluntário, aquele que é constituído por livre manifestação de vontade das partes, dependendo do preenchimento de alguns requisitos legais, quais sejam: o instituidor do bem de família deve ser proprietário do bem; deve haver destinação específica para moradia da família; e, por fim, o instituidor deve ser solvente. Cumpre ressaltar que tal modalidade se perfaz através de Escritura Pública registrada em Cartório.

A Medida Provisória e, posteriormente, sua conversão em lei, é fruto de um momento delicado pelo qual atravessava o país no fim dos anos 80 e início da década de 90, com grande crise econômica e alta inflação, razões pelas quais se fazia necessária a criação de instrumentos jurídicos claros que dessem ao cidadão a proteção à moradia, como forma de efetivação do princípio da dignidade da pessoa humana, valor fundamental da Constituição de 1988.

Do conteúdo da Lei 8.009/90, para configuração do bem de família e consequente impenhorabilidade, necessária a observância de requisitos como propriedade do bem e a destinação específica. Importante destacar que, para caracterização de bem de família, não há nenhuma limitação legal em relação ao valor ou extensão do bem, sendo a impenhorabilidade oponível em qualquer processo de execução.

Necessário ressaltar que a própria lei dispõe sobre algumas exceções à impenhorabilidade:

Art. $3^{\circ} \mathrm{A}$ impenhorabilidade é oponível em qualquer processo de execução civil, fiscal, previdenciária, trabalhista ou de outra natureza, salvo se movido: I - Revogado

\footnotetext{
4 Art. 1.711. Podem os cônjuges, ou a entidade familiar, mediante escritura pública ou testamento, destinar parte de seu patrimônio para instituir bem de família, desde que não ultrapasse um terço do patrimônio líquido existente ao tempo da instituição, mantidas as regras sobre a impenhorabilidade do imóvel residencial estabelecida em lei especial.

Parágrafo único. O terceiro poderá igualmente instituir bem de família por testamento ou doação, dependendo a eficácia do ato da aceitação expressa de ambos os cônjuges beneficiados ou da entidade familiar beneficiada.
} 
II - pelo titular do crédito decorrente do financiamento destinado à construção ou à aquisição do imóvel, no limite dos créditos e acréscimos constituídos em função do respectivo contrato;

III - pelo credor da pensão alimentícia, resguardados os direitos, sobre o bem, do seu coproprietário que, com o devedor, integre união estável ou conjugal, observadas as hipóteses em que ambos responderão pela dívida;

IV - para cobrança de impostos, predial ou territorial, taxas e contribuições devidas em função do imóvel familiar;

V - para execução de hipoteca sobre o imóvel oferecido como garantia real pelo casal ou pela entidade familiar;

VI - por ter sido adquirido com produto de crime ou para execução de sentença penal condenatória a ressarcimento, indenização ou perdimento de bens.

VII - por obrigação decorrente de fiança concedida em contrato de locação. (BRASIL, 1990)

Parece evidente que a Lei 8.009/90 não teve a intenção de estimular a má-fé do devedor, imputando um escudo de proteção que impeça efetivamente a satisfação do credor. A despeito disso, é nítido o caráter social que a lei assume, coadunando-se, perfeitamente, com a Constituição de 1988, na perspectiva da proteção da família e da moradia.

Assim, é possível considerar que a lei mencionada é um mecanismo efetivo para "[...] garantir as condições mínimas de sobrevivência digna a salvo da execução por dívidas, avolumadas, em grande parte, não pela voracidade consumista do devedor, mas pelos tormentos e desastres de uma economia cronicamente conturbada como é a de nosso país”. (CZAJKOWSKI, 2002, p. 18).

A despeito de todos os contornos delineados até o presente momento, necessário destacar que a proteção ao bem de família vem sendo objeto de vasta discussão doutrinária e jurisprudencial, sendo possível relativização do instituto sempre pautada numa análise a partir do princípio da boafé, motivo pelo qual se mostra fundamental a abordagem específica sobre, como tal princípio se irradia no sistema jurídico vigente.

\section{A IRRADIAÇÃO DO PRINCÍPIO DA BOA-FÉ OBJETIVA NO SISTEMA JURÍDICO}

A postura crítico-reflexiva sobre a flexibilização da impenhorabilidade do bem de família, da forma como vem sendo tratada pelas decisões mais recentes do Superior Tribunal de Justiça, faz-se necessário estreitar a atenção sobre o princípio da boa-fé, vez ser esse o vetor principiológico de maior importância para a discussão que ora se apresenta.

\subsection{Princípio Da Boa-Fé ObJetiva: Aspectos Constitucionais E Sua Irradiação No Direito CiviL}

É fato que a Constituição Federal de 1988 é eminentemente principiológica, repleta de valores éticos e, daí é possível vislumbrar que o princípio da boa-fé objetiva é sim corolário 
constitucional, existindo grande dificuldade de se estabelecer um mecanismo interpretativo concreto e eficaz sobre o que vem a ser boa-fé.

Há certo consenso em afirmar que a boa-fé se origina no direito romano, na caracterização da "bona fides" e da "fides bona" (PEIXOTO, 2003, p. 142). O entendimento sobre o que vem a ser boa-fé vai seguindo os contornos de cada época da história da humanidade, a depender do centro de força e poder de cada época.

Para o propósito do presente trabalho, pertinente se ater à ideia de boa-fé na Idade Moderna, especialmente a partir da ascensão burguesa no contexto da Revolução Francesa, com a centralização no indivíduo, a partir das concepções de liberdade, igualdade e fraternidade, passando a serem incorporados elementos relativos à autonomia da vontade e ao distanciamento do Estado das interferências nos pactos privados.

Afirma Rosenvald (2005, p. 77), que "do ideário clássico da Revolução Francesa, "liberdade, igualdade e fraternidade", a burguesia se apossou dos dois primeiros valores e comodamente se esqueceu do dever de solidariedade".

Esse contexto influenciou as Constituições pelo mundo afora, sendo o âmbito nacional marcado pela tendência teórica de dicotomia absoluta entre o público e o privado, assumindo o Código Civil de 1916, claramente de valores liberais, individuais e egoístas, relevante preponderância no que tange ao retardamento da expansão da boa-fé objetiva.

Nota-se que, somente com a Constituição Federal de 1988 e, posteriormente, com a promulgação do Código Civil de 2002, o princípio da boa-fé começa a balizar a, até então, absoluta autonomia da vontade, refletida na liberdade de contratar. Neste momento, no Brasil, começa a ruir a concepção dura do pacta sunt servanda.

A constitucionalização do Direito, faz com que se espalhe por todo o ordenamento jurídico concepções calcadas na centralização da dignidade da pessoa humana, fazendo com que ramos, tradicionalmente classificados como sendo de direito privado, fossem objeto de grande ressignificação, aqui destacando o Direito Civil e o Direito Processual Civil. Luis Roberto Barroso defende a ideia no sentido de que "essa constitucionalização, potencializada pelo contexto filosófico do pós-positivismo - centralidade da ideia de dignidade humana e dos direitos fundamentais [...], tem tornado o debate jurídico atual extremamente rico e instigante" (BARROSO, 2009, p. 86).

A boa-fé passa, assim, a ser analisada a partir de diversas perspectivas, caracterizando-se como princípio constitucional implícito, norte ético que informa todo o ordenamento jurídico.

A partir das disposições constitucionais e infraconstitucionais (Código Civil de 2002), afirma-se que há a divisão da boa-fé em dois prismas: subjetiva e objetiva. Para Judith Martins (2000, p. 16), a boa-fé subjetiva é fundada na concepção na qual o sujeito desconhece o caráter ilícito de sua conduta, enquanto na objetiva há a consideração de que o sujeito não se encontra protegido por eventual erro ou desconhecimento sobre a inadequação de seu comportamento.

A boa-fé objetiva se justifica na necessidade coletiva de as pessoas pautarem suas condutas em conformidade com a honestidade e retidão, concretizando, reflexamente, os princípios constitucionais implícitos e explícitos que se ligam à dignidade da pessoa humana, solidariedade 
e justiça social. Segundo Paulo Lobo (2018), a boa-fé, como princípio fundamental do direito civil, deve contemplar três dimensões: critério essencial de interpretação normativa e negócios jurídicos; limitação da autonomia privada; e dever geral de conduta obrigacional. Nesse contexto, o Código Civil de 2002 acabou por incorporar a boa-fé objetiva em alguns dispositivos, tais como o artigos, $113^{5}, 187^{6}$ e $422^{7}$.

No diploma civil vigente a "boa-fé deixa o campo das ideias, da intenção - boa-fé subjetiva -, e ingressa no campo dos atos, das práticas de lealdade - boa-fé objetiva” (TARTUCE, 2005, p. 1). É por isso que, para o presente trabalho, ao se referir ao princípio da boa-fé, está-se a mencionar a boa-fé objetiva, inserta na norma infraconstitucional a partir da perspectiva constitucional vigente, conforme anteriormente assentado.

Não é possível restringir o princípio da boa-fé aos particulares. Os magistrados, responsáveis diretos e últimos pela a interpretação e aplicação das normas aos fatos concretos, também são destinatários do princípio. O Código Civil de 2002 confere ao magistrado, tanto o poder de suprir eventuais lacunas legislativas, como também de resolver a partir de uma perspectiva de conformidade com valores éticos.

\subsection{Princípio Da Boa-Fé Processual À Luz Do Código De Processo Civil De 2015}

Analisado o princípio da boa-fé objetiva a partir do texto constitucional e do diploma civil promulgado em 2002, cumpre neste momento vislumbrar de que forma tal princípio foi tratado pelo Código de Processo Civil, especialmente no momento de alteração profunda no sistema processual, com a entrada em vigor do diploma processual de 2015.

A partir da constitucionalização das mais importantes garantias processuais, houve a construção de um modelo de processo pautado a partir do princípio do devido processo legal, responsável por conduzir as partes à efetiva entrega da tutela jurisdicional por parte do Estadojuiz. Nelson Nery Junior (2016, p. 106) afirma que "o princípio constitucional fundamental do processo civil, que entendemos como a base sobre a qual todos os outros princípios e regras se sustentam, é o do devido processo legal, expressão oriunda da inglesa due process of law”.

Trata-se assim do princípio dos princípios, insculpido no art. 5º LIV da Constituição

Federal, ao prever que ninguém deve ser privado de sua liberdade ou bens sem o devido processo

legal, comportando-se a ordem constitucional e a seara processual em constante processo de troca:

5 Art. 113. Os negócios jurídicos devem ser interpretados conforme a boa-fé e os usos do lugar de sua celebração.

$\S 1^{\circ}$ A interpretação do negócio jurídico deve lhe atribuir o sentido que:

I - for confirmado pelo comportamento das partes posterior à celebração do negócio;

II - corresponder aos usos, costumes e práticas do mercado relativas ao tipo de negócio;

III - corresponder à boa-fé;

IV - for mais benéfico à parte que não redigiu o dispositivo, se identificável; e

$\mathrm{V}$ - corresponder a qual seria a razoável negociação das partes sobre a questão discutida, inferida das demais disposições do negócio e da racionalidade econômica das partes, consideradas as informações disponíveis no momento de sua celebração.

$\S 2^{\circ}$ As partes poderão livremente pactuar regras de interpretação, de preenchimento de lacunas e de integração dos negócios jurídicos diversas daquelas previstas em lei.

6 Art. 187. Também comete ato ilícito o titular de um direito que, ao exercê-lo, excede manifestamente os limites impostos pelo seu fim econômico ou social, pela boa-fé ou pelos bons costumes.

7 Art. 422. Os contratantes são obrigados a guardar, assim na conclusão do contrato, como em sua execução, os princípios de probidade e boa-fé. 
In our world of ever-growing complexity, fundamental procedural principles and rights - often of constitutional origin and nature - have gained a leading role since they are such an essential and necessary condition for the exercise of other fundamental rights. Their growing constitutional and/or fundamental nature can be acknowledged with satisfaction. Procedure has become a "noble subject matter" (FERRAND, 2004, p. 58)

O Código de Processo Civil de 2015 inovou ao tratar, em capítulo próprio, intitulado de "Normas Fundamentais do Processo Civil", de uma série de comandos com alto grau de fundamentabilidade e, que, a partir da ideia de devido processo legal, trazem para o contexto normativo infraconstitucional, claro alinhamento com a Constituição de 1988, acrescentando-se algumas normas fundamentais que se coadunam com o processo civil contemporâneo.

Destaca-se a previsão expressamente trazida no art. $5^{\circ}$ do Código de Processo Civil(BRASIL, 2015), dispondo que "aquele que, de qualquer forma participa do processo deve comportar-se de acordo com a boa-fé". Tem-se aí a lealdade processual, com amparo constitucional no princípio do devido processo legal, tal como observado anteriormente.

É evidente que, a obrigação de agir de maneira leal e ética, é direcionada a todos os sujeitos da relação jurídica processual, ou seja, partes, juiz, auxiliares etc., uma vez que o objetivo elementar está voltado à entrega da tutela jurisdicional mais efetiva e justa possível.

A questão que se coloca neste momento é a de identificar se o diploma processual se refere à boa-fé objetiva ou subjetiva, nos termos do que foi explanado no tópico anterior. Enfrentar tal questão exige examinar a relação processual como sendo uma relação jurídica, na qual é imposto aos sujeitos o dever de se comportar de maneira proba e ética, razão por que defende-se a ideia de que o CPC rata de boa-fé objetiva.

Nesse sentido, o Enunciado n. 374, do Fórum Permanente de Processualistas Civil, dispõe que o art. $5^{\circ}$ prevê a boa-fé objetiva. Nessa linha, a tríplice função da boa-fé objetiva delineada no tópico anterior - interpretativa, integrativa e limitadora - aplica-se perfeitamente ao processo civil (ENUNCIADOS..., 2019).

A análise da boa-fé no contexto do processo civil se mostra fundamental, uma vez que a flexibilização da proteção legal destinada ao bem de família só pode ocorrer a partir da existência de um processo judicial, onde sejam resguardados todos os direitos fundamentais dos sujeitos processuais. Assim, a concepção e a interpretação do princípio da boa-fé, tanto no âmbito material quanto no processual, impactam definitivamente na proteção ao bem de família, tal qual será demonstrado a seguir.

\footnotetext{
$8 \mathrm{Em}$ nosso mundo de complexidade sempre crescente, os princípios e direitos processuais fundamentais - muitas vezes de origem e natureza constitucional - ganharam um papel de liderança por serem uma condição tão essencial e necessária para o exercício de outros direitos fundamentais. Sua crescente natureza constitucional e/ou fundamental pode ser reconhecida com satisfação. O procedimento tornou-se uma "matéria nobre" (tradução nossa)
} 


\section{A INTERPRETAÇÃO DO PRINCÍPIO FUNDAMENTAL DA BOA-FÉ E OS IMPACTOS NA PROTEÇÃO AO BEM FAMÍLIA}

Há significativa relevância de reconhecimento do grau de importância dos princípios para um sistema jurídico pautado na supremacia constitucional, sendo evidente a força normativa que a Constituição Federal de 1988 possui.

A Constituição principiológica faz todo o sentido, na medida em que estes comandos deixam de ser considerados meras diretrizes contemplativas e passam a ser considerados vetores de aplicação e efetivação das normas constitucionais. Assim, é preciso reconhecer aos princípios o alto grau de fundamentabilidade que os mesmos possuem, na medida em que se revelam parâmetro normativo para todo o conjunto normativo que compõe o sistema.

Falar de princípio como norma é, justamente, revelar a necessidade de ser encontrado um parâmetro interpretativo adequado, uma vez que norma é parte de um texto interpretado (CANOTILHO, 2004, p. 214). Assim, no presente trabalho, entende-se princípio como norma jurídica, especificamente como mandamentos de otimização, ou seja, normas que devem ser realizadas na maior medida possível (ALEXY, 2001, p. 86). Tal visão é fundamental para que o princípio da boa-fé possa ser devidamente analisado no contexto de flexibilização da impenhorabilidade do bem de família.

A atividade interpretativa, hermenêutica, direcionada para os princípios constitucionais, é fundamental para que os preceitos basilares sejam efetivados na máxima essência possível. O grande desafio que se apresenta repousa, justamente, na importância da atividade jurisdicional, ao interpretar os textos normativos à luz dos preceitos constitucionais. O que mais à frente será abordado é, justamente, sobre a interpretação que os tribunais vêm dando acerca da impenhorabilidade do bem de família, à luz do princípio da boa-fé.

O desafio do Direito na atualidade dentre outros, está vinculado à questão hermenêutica. Para Heidegger a hermenêutica nada mais é do que o "estudo do compreender". A definição é simples, mas extremamente valiosa, na medida que a essência da atividade hermenêutica repousa na necessidade de "descobrir atrás da linguagem o sentido radical, ou seja o discurso" (HEIDEGGER, 2005, p. 200).

O equilíbrio interpretativo se faz necessário, conforme menciona Rafael de Lazari:

O fenômeno constitucionalista não está livre de equívocos, contudo, e prova disso é a necessidade de se readequar alguns excessos do neoconstitucionalismo [...]. Por tal razão, correntes buscam alternativas para o futuro, dentre as quais se destaca o "constitucionalismo do futuro" (ou "constitucionalismo vindouro"), desenvolvido por José Roberto Dromi, e suas sete premissas fundamentais: verdade, solidariedade, consenso, continuidade, participação, integração e universalização. (LAZARI, 2016, p. 80)

Entende-se aqui que a melhor interpretação da norma jurídica se realiza quando há possibilidade plena de concretização dos fins e preceitos previstos na Constituição Federal, dentro 
da lógica da supremacia constitucional. Assim, os institutos de direito civil e processual civil, por exemplo, devem ser interpretados a partir da Constituição, até mesmo pelo fato de que os preceitos constitucionais estão refletidos de maneira muito intensa nesses diplomas normativos infraconstitucionais.

Teresa Negreiros afirma que "a releitura da dogmática civil à luz da Constituição, com base na sua funcionalização à promoção dos valores existenciais, sugere que a utilidade dos bens seja igualmente considerada em função da sua utilidade para a pessoa que deles necessita" (NEGREIROS, 2006, p. 383).

Sendo o princípio da boa-fé objetiva considerado princípio constitucional, é papel do Poder Judiciário a aplicação do mesmo, tanto numa perspectiva de direito material como também de direito processual, tal como foi assentado anteriormente em decorrência das previsões expressas contidas no Código Civil e no Código de Processo Civil.

Especificamente, sobre a impenhorabilidade do bem de família, faz-se necessário atentar para o art. $833^{9}$ do Código de Processo Civil vigente; dispositivo responsável por elencar algumas situações em que a responsabilidade patrimonial encontra óbices para ser efetivada, isso porque a mesma tem uma baliza evidentemente clara: o princípio da dignidade da pessoa humana. É por tal razão que a execução, e sua consequente responsabilidade patrimonial, não pode aniquilar as capacidades econômicas de próprio sustento do executado, nem deixar o mesmo carente de um direito básico: o de moradia.

José Miguel Garcia Medina (2015, p. 736) lembra que as medidas executivas previstas na legislação processual devem ser interpretadas justamente conforme a Constituição Federal, a partir do princípio da proporcionalidade.

A questão que se apresenta relevante trata de considerar que o conjunto de situações abrangidas pela proteção patrimonial constante do art. 833 do CPC não deve ser tratado de maneira absoluta, tal como observam André Medeiros Toledo e Elias Marques de Medeiros Neto ao afirmarem que:

9 Art. 833. São impenhoráveis:

I - os bens inalienáveis e os declarados, por ato voluntário, não sujeitos à execução;

II - os móveis, os pertences e as utilidades domésticas que guarnecem a residência do executado, salvo os de elevado valor ou os que ultrapassem as necessidades comuns correspondentes a um médio padrão de vida;

III - os vestuários, bem como os pertences de uso pessoal do executado, salvo se de elevado valor;

IV - os vencimentos, os subsídios, os soldos, os salários, as remunerações, os proventos de aposentadoria, as pensões, os pecúlios e os montepios, bem como as quantias recebidas por liberalidade de terceiro e destinadas ao sustento do devedor e de sua família, os ganhos de trabalhador autônomo e os honorários de profissional liberal, ressalvado o $\S$ $2^{\circ}$

$\mathrm{V}$ - os livros, as máquinas, as ferramentas, os utensílios, os instrumentos ou outros bens móveis necessários ou úteis ao exercício da profissão do executado;

VI - o seguro de vida;

VII - os materiais necessários para obras em andamento, salvo se essas forem penhoradas;

VIII - a pequena propriedade rural, assim definida em lei, desde que trabalhada pela família;

IX - os recursos públicos recebidos por instituições privadas para aplicação compulsória em educação, saúde ou assistência social;

X - a quantia depositada em caderneta de poupança, até o limite de 40 (quarenta) salários-mínimos;

XI - os recursos públicos do fundo partidário recebidos por partido político, nos termos da lei;

XII - os créditos oriundos de alienação de unidades imobiliárias, sob regime de incorporação imobiliária, vinculados à execução da obra. 
Vê-se, diante de todo o plexo protetivo do art. 833 do CPC/15, que as hipóteses de impenhorabilidade são consentâneas com o princípio da dignidade da pessoa humana. Todavia, tais cláusulas não tendem a serem absolutas. Pelo contrário: a sua relativização, a depender do caso sob exame, deve ser realçada, à medida que a dignidade resguardada e protegida pelo sistema processual-constitucional não se limita ao executado. (TOLEDO; MEDEIROS NETO, 2018, p. 3)

Se a impenhorabilidade prevista no art. 833 do CPC/15 não é absoluta, poder-se-ia afirmar que a impenhorabilidade do bem de família, previsto em legislação específica (Lei. 8009/90), também não guarda característica de o ser, podendo ser flexibilizada, a partir do caso concretamente sob análise. Essa foi a defesa construída ao longo dos anos na doutrina e que começou a ganhar espaço no âmbito dos tribunais brasileiros recentemente.

Ocorre que, ao longo do tempo, verifica-se uma série de mudanças interpretativas sobre o instituto do bem de família, sendo que, recentemente, o Superior Tribunal de Justiça, julgando o Resp. 1.559.348 (BRASIL, 2019a), entendeu pela inaplicabilidade da impenhorabilidade do bem de família no caso de violação do princípio da boa-fé objetiva.

O ministro Luís Felipe Salomão, relator do recurso mencionado, afirmou não se admitir a proteção irrestrita do bem de família caso essa tutela significar o "alijamento da garantia após o inadimplemento do débito, contrariando a ética e a boa-fé, indispensáveis em todas as relações negociais" (BRASIL, 2019a). Acrescentando ainda o relator que:

O abuso do direito de propriedade, a fraude e a má-fé do proprietário devem ser reprimidos, tornando ineficaz a norma protetiva, que não pode conviver, tolerar e premiar a atuação do agente em desconformidade com o ordenamento jurídico. (BRASIL, 2019a)

O caso em julgamento revelava situação em que devedores fizeram a opção livre de dar seu único imóvel em garantia, não existindo provas de que tenha ocorrido algum vício de consentimento, motivo pelo qual o princípio da boa-fé contratual impõe aos contratantes o dever de honrar com o pactuado.

Importante relembrar que a proteção legal do bem de família é matéria de ordem pública, ou seja, irrenunciável. Ainda assim, no julgamento citado, o Superior Tribunal de Justiça caminhou no sentido de que a regra da impenhorabilidade não se aplica para situações em que resta configurado o abuso do direito de propriedade. No caso concreto, o abuso de direito estaria configurado na medida em que houve a livre indicação do imóvel único como garantia, ou seja, impondo a boa-fé contratual a necessidade de respeito ao pactuado.

Seguindo a mesma linha, mais recentemente, em novembro de 2019, novamente o Superior Tribunal de Justiça voltou a enfrentar a questão da impenhorabilidade do bem de família, tendo-a afastado por entender que haveria ocorrido violação da boa-fé objetiva. Esse foi o entendimento da Ministra Nancy Andrighi, relatora do Recurso Especial n. 1.782.227 (BRASIL, 2019b). Eis a ementa do julgado: 
DIREITO CIVIL. RECURSO ESPECIAL. AÇÃO DE EXECUÇÃO DE TÍTULO EXECUTIVO EXTRAJUDICIAL. BEM IMÓVEL RECONHECIDO COMO BEM DE FAMÍLIA DADO EM GARANTIA DO CUMPRIMENTO DE ACORDO HOMOLOGADO JUDICIALMENTE. POSSIBILIDADE. CONDUTA QUE FERE A ÉTICA E A BOA-FÉ. 1. Ação de execução de título executivo extrajudicial - nota promissória. 2. Ação ajuizada em 11/06/2010. Recurso especial concluso ao gabinete em 07/05/2018. Julgamento: CPC/2015. 3. O propósito recursal é dizer se é válido o oferecimento de bem de família como garantia ao cumprimento de acordo pactuado e homologado judicialmente nos autos de ação de execução por quantia certa. 4. A questão da proteção indiscriminada do bem de família ganha novas luzes quando confrontada com condutas que vão de encontro à própria ética e à boa-fé, que devem permear todas as relações negociais. 5. Não pode o devedor ofertar bem em garantia que é sabidamente residência familiar para, posteriormente, vir a informar que tal garantia não encontra respaldo legal, pugnando pela sua exclusão (vedação ao comportamento contraditório). 6 . Tem-se, assim, a ponderação da proteção irrestrita ao bem de família, tendo em vista a necessidade de se vedar, também, as atitudes que atentem contra a boa-fé e a eticidade, ínsitas às relações negociais. 7 . Recurso especial conhecido e não provido.

Parece evidente que o Superior Tribunal de Justiça vem adotando linha interpretativa no sentido de, utilizando-se da técnica de ponderação, analisar o caso concreto para verificar eventual violação ao princípio da boa-fé objetiva, especialmente no que tange aos contratos.

\section{PRINCÍPIO DA PONDERAÇÃo}

Parece haver acentuado risco na interpretação e posicionamento acima exposto, especialmente em se considerando que os contratos devem ser pautados em outro princípio, qual seja, o da função social. As recentes decisões do Superior Tribunal de Justiça, sob o argumento interpretativo de eventual violação ao princípio da boa-fé contratual, parecem ressuscitar o caráter prevalecente da autonomia da vontade e liberdade contratual sobre a função social.

Nessa perspectiva, importante destacar noção sobre o paradigma da essencialidade, perfeitamente aplicado à questão da penhora do bem de família, com vistas a afastar ou não a impenhorabilidade. Sobre o tema, Jussara Nasser Ferreira e Larissa Costa (2018, p. 250) destacam que o paradigma da essencialidade "encontra fundamento na tutela da dignidade da pessoa humana, impondo também à teoria contratual o reconhecimento de interesses extrapatrimoniais nas relações contratuais".

Frise-se, também, Luciano Timm, ao afirmar:

O novo Código Civil brasileiro (NCC), que foi publicado em 2002 e entrou em vigor em 2003, introduziu significativas inovações no Direito Privado no Brasil. Inovações não do ponto de vista quantitativo (número de artigos), mas, sim, 
modificações qualitativas (no conteúdo das normas). Sem dúvida, a cláusula mais controvertida é a que consta no artigo 421, que assim dispõe: "A liberdade de contratar será exercida em razão e nos limites da função social do contrato". (TIMM, 2009, p. 2)

Mariana Ribeiro Santiago e Lívia Gaigher Bósio Campello (2016, p. 120) ressaltam que "a Constituição Federal de 1988 materializa a noção de limitação da iniciativa privada e da propriedade[...]". Nota-se, assim, que a partir do recente entendimento esposado pelo Superior Tribunal de Justiça, a impenhorabilidade do bem de família não se apresenta como cláusula absoluta, devendo ceder espaço para uma das cláusulas gerais do Direito Civil, qual seja a boa-fé objetiva nos contratos, relativizando-se até mesmo a ideia de função social do contrato, paradigma constitucional e legal vigente.

\section{CONCLUSÃO}

O problema enfrentado na presente pesquisa coloca em discussão preceitos constitucionais de extrema relevância. Discute-se dignidade da pessoa humana, direito à moradia, função social dos contratos e boa-fé objetiva, sendo que todos esses valores refletem diretamente na construção do sistema jurídico como um todo.

A proteção ao bem de família, além de tratamento dado pelo legislador infraconstitucional, encontra resguardo essencialmente no contexto constitucional vigente, especialmente no que tange à proteção da dignidade da pessoa humana e na efetivação do direito constitucional de moradia. Importante destacar que é com base nessa perspectiva que o próprio conceito de bem de família passou por transformações ao longo do tempo, na busca da maior efetivação possível.

Há flexibilização à proteção do bem de família na medida em que o Superior Tribunal de Justiça afastou a impenhorabilidade em razão de ofensa ao princípio da boa-fé objetiva nas relações contratuais, revela opção interpretativa que desconsidera a fundamento constitucional do instituto que protege os bens imóveis em razão de sua essencialidade. Argumenta-se que, estariam sendo privilegiados outros valores constitucionais e infraconstitucionais, na medida em que a boafé objetiva se apresenta tanto no Código Civil quanto no Código de Processo Civil como norma fundamental.

Verifica-se que, tal como acontece com o direito, amoldando-se cotidianamente ao fito de se dar guarida aos apelos denotados nas relações sociais, a norma jurídica é dinâmica, transformandose na medida em que peculiaridades lhes são apresentadas, absorvendo vasta gama de valores e princípios ao alcance da pretensa Justiça.

Apesar desta peculiaridade se portar hígida, justificável e típica, há de asseverar que os posicionamentos judiciais podem se revelar preocupantes na medida em que se opta por interpretações fortemente discutíveis, ponderando pela prevalência de um princípio constitucional como o da boa-fé sobre o princípio fundamental da Constituição, qual seja o da dignidade da 
pessoa humana, em nítida afronta ao direito fundamental de proteção à moradia.

Conclui-se que a atividade interpretativa direcionada para os princípios constitucionais é fundamental para que os preceitos basilares sejam efetivados na máxima essência possível. O grande desafio é encontrar um adequado ajuste interpretativo sobre a questão da impenhorabilidade do bem de família, sopesando-se, evidentemente, toda e qualquer valoração, desde que se produzam normas jurídicas capazes de refletir no seio das intransigências sociais a necessária segurança jurídica, extraindo-se, em potencialidade, o que melhor se tem de base principiológica à razão de suas correspondentes atribuições.

\section{REFERÊNCIAS}

ALEXY, Robert. Teoría del discurso y derechos humanos. Bogotá: Universidad Externado de Colômbia, 2001.

BRASIL. [Constituição Federal (1988)]. Constituição da República Federativa do Brasil. Brasília: Presidência da República, 1988. Disponível em: http://www.planalto.gov.br/ccivil_03/ constituicao/constituicao.htm. Acesso em: 01 de ago. 2019.

BRASIL. Lei no 8.009, de 29 de março de 1990. Dispõe sobre a impenhorabilidade do bem de família. Brasília: Presidência da República, 1990. Disponível em: http://www.planalto.gov.br/ ccivil_03/leis/L8009.htm. Acesso em: 01 de ago. 2019.

BRASIL. Supremo Tribunal de Justiça (4 Turma). Recurso Especial

1.559.348. Acórdão publicado em 05 de agosto de 2019a. Relator: Min.

Luis Felipe Salomão. Disponível em: https://ww2.stj.jus.br/processo/revista/ documento $/$ mediado $/$ ?componente $=$ ITA\&sequencial $=1777349 \&$ num registro $=201502459832 \&$ data $=20190805 \&$ formato=PDF. Acesso em: 05 de ago. 2019.

BRASIL. Supremo Tribunal de Justiça (3 Turma). Recurso Especial

1.782.227. Acórdão publicado em 29 de agosto de 2019b. Relatora: Min. Nancy Andrighi. Disponível em: https://ww2.stj.jus.br/processo/revista/ documento/mediado/?componente $=$ ATC\&sequencial $=100313417 \&$ num registro $=201800958190 \&$ data $=20190829 \&$ tipo $=5 \&$ formato $=$ PDF. Acesso em: 26 nov. 2019.

CANOTILHO, José Joaquim Gomes. Direito constitucional e teoria da constituição. 7. ed. Coimbra: Almedina, 2004.

CZAJKOWSKI, Rainer. A impenhorabilidade do bem de família: comentários à 65 Lei 8.009/90. 4. ed. Curitiba: Juruá, 2002.

DINIZ, Maria Helena. Curso de direito civil brasileiro. 33. ed. São Paulo: Saraiva, 2019. v.5.

DUTRA, Maristela Aparecida; BORGES, Fernanda Aparecida. Impenhorabilidade do bem de família. Revista Jurídica do UNIARAXÁ, Araxá, v. 21, n. 20, p. 245-268, ago. 2017. 
Disponível em: Acesso em: 27 nov. 2019.

FACHIN, Luiz Edson. Estatuto jurídico do patrimônio mínimo. Rio de Janeiro: Renovar, 2001.

ENUNCIADOS do Fórum Permanente de Processualistas Civis- Carta de Florianópolis. Florianópolis, 2017. Disponível em: https:/institutodc.com.br/wp-content/uploads/2017/06/ FPPC-Carta-de-Florianopolis.pdf. Acesso em: 28 nov. 2019.

FERRAND, Frédérique. Ideological background of the constitution, constitutional rules and civil procedure. In: INTERNATIONAL ASSOCIATION OF PROCEDURAL LAW SEOUL CONFERENCE, 2014. Seul: IAPL, 2014.

FERREIRA, Jussara Suzi Assis Borges Nasser; COSTA, Larissa Aparecida. Contratos privados de assistência à saúde: paradigma da essencialidade. Prisma Jurídico. São Paulo, v. 17, n. 1, p. 227-254, 2018. Disponível em: https://periodicos.uninove.br/index. php?journal=prisma\&page=article \&op=view\&path $\% 5 \mathrm{~B} \% 5 \mathrm{D}=8144 \&$ path $\% 5 \mathrm{~B} \% 5 \mathrm{D}=3815$. Acesso em: 20 nov. 2019.

FRANÇA, Limongi. Instituições de direito civil. São Paulo: Saraiva, 1988.

HEIDEGGER, Martin. Ser e tempo: parte II. 13. ed. São Paulo: Vozes, 2005.

LAZARI, Rafael de. A hermenêutica e o futuro do constitucionalismo. In: MARGRAF, Rafael de Lazari; LAZARI, Rafael de (org.). Hermenêutica constitucional: desafios para uma interpretação efetiva. Rio de Janeiro: Lumen Juris, 2016.

LOBO, Paulo. Boa-fé entre o princípio jurídico e o dever geral de conduta obrigacional. GENJURIDICO, São Paulo, 28 fev. 2018. Disponível em: http://genjuridico.com.br/2018/02/26/ boa-fe-do-administrado-e-do-administrador-como-fator-limitativo-da-discricionariedadeadministrativa/. Acesso em: 27 nov. 2019.

MEDINA, José Miguel Garcia. Novo código de processo civil comentado. $1^{\text {a }}$ ed. São Paulo: Editora Revista dos Tribunais, 2015.

NEGREIROS, Teresa. Teoria do contrato. Rio de Janeiro: Renovar, 2006.

PEIXOTO, Ester Lopes. O princípio da boa-fé no direito civil brasileiro. Revista de direito do consumidor. São Paulo: Revista dos Tribunais, n. 45, p. 140-171, jan-mar 2003.

ROSENVALD, Nelson. Dignidade humana e boa-fé no Código Civil. 1. ed. Saraiva, 2005.

SANTIAGO, Mariana Ribeiro; CAMPELLO, Lívia Gaiguer Bósio. Função social e solidária da empresa na dinâmica da sociedade de consumo. Revista Scientia Iuris, Londrina, v. 20, n. 1, p. 119-143, abr. 2016. Disponível em:https://www.researchgate.net/publication/303292332_ Funcao_social_e_solidaria_da_empresa_na_dinamica_da_sociedade_de_consumo. Acesso em: 20 nov. 2019. 
SARLET, Ingo Wolfgang. Dignidade da pessoa humana e direitos fundamentais. Porto Alegre: Livraria do Advogado, 2001.

TARTUCE, Flávio. O princípio da boa-fé objetiva no Direito de Família. In: CONGRESSO BRASILEIRO DE DIREITO DE FAMÍLIA DO IBDFAM, 5, 2005, Belo Horizonte. Anais [...]. Belo Horizonte: IBDFAM, 2015Disponível em: http://www.ibdfam.org.br/assets/upload/ anais/48.pdf. Acesso em: 27 nov. 2019.

TIMM, Luciano Benetti. Ainda sobre a função social do Direito Contratual no Código Civil brasileiro: justiça distributiva versus eficiência econômica. Revista da AMDE, v. 2, [s.1.], p. 1-40, 2009. Disponível em: http://www.revista.amde.org.br/index.php/ramde/article/view/26/24. Acesso em: 26 de jul. 2019.

TOLEDO, André Medeiros; MEDEIROS NETO, Elias Marques. Proposta de uma possível relativização da impenhorabilidade do bem de família, Revista Eletrônica de Direito Processual - REDP, Rio de Janeiro, v. 19. n. 2., maio/ago. 2018, p. 1-47. Disponível em: www. redp.uerj.br. Acesso em: 20 nov. 2019.

Como citar: FERREIRA, Jussara Borges; OLIVEIRA, Maria das Graças Macena Dias de; GERMINARI, Jefferson Patrik. O princípio da boa-fé e os reflexos sobre a proteção ao bem de família: aspectos materiais e processuais. Revista do Direito Público, Londrina, v. 16, n. 3, p.227244, dez. 2021. DOI: 10.5433/24157-108104-1.2021v16n3p.227. ISSN: 1980-511X

Recebido em: 13/07/2020

Aprovado em: 10/03/2021 